\title{
Social acceptability of treatments for adolescent idiopathic scoliosis: a cross-sectional study Stefano Negrini ${ }^{* 1}$ and Roberta Carabalona ${ }^{2}$
}

Address: ${ }^{1}$ ISICO (Italian Scientific Spine Institute), Via Carlo Crivelli 20, 20122 Milan, Italy and ${ }^{2}$ Don Carlo Gnocchi Foundation ONLUS, Care \& Research Institute, Via Capecelatro 66, 20148 Milan, Italy

Email: Stefano Negrini* - stefano.negrini@isico.it; Roberta Carabalona - taichirobi@yahoo.com

* Corresponding author

Published: 24 August 2006

Scoliosis 2006, I:14 doi:10.1/86/1748-7|6I-I-14

This article is available from: http://www.scoliosisjournal.com/content/l/I/I4

(c) 2006 Negrini and Carabalona; licensee BioMed Central Ltd.

This is an Open Access article distributed under the terms of the Creative Commons Attribution License (http://creativecommons.org/licenses/by/2.0), which permits unrestricted use, distribution, and reproduction in any medium, provided the original work is properly cited.
Received: 26 April 2006

Accepted: 24 August 2006

\begin{abstract}
Background: There are no data on social acceptability of scoliosis. Aim. To elicit evidence-based opinions on therapeutic strategies for adolescent idiopathic scoliosis in a sample of families with not affected children, so to understand the social perception of this issue.

Methods: Design. Cross-sectional study. Setting. Secondary schools in 4 northern Italian regions. Participants. Parents of children in the age group at risk of and not affected by scoliosis (Pre-test group $=100$, Study group $=3,162$ ). Interventions. Questionnaire: five specific and evidence-based questions regarding scoliosis treatment options and a socio-demographic section. Methodology. "Role-playing" in which it was required to normal people to answer what they would have chosen if they had been in the situation proposed. Main outcome measures. Perception of acceptability of treatments for adolescent idiopathic scoliosis in the general population (social acceptability)
\end{abstract}

Results: The families support the use of screening (94.8\%) at school, immediate bracing (76.4\%) for scoliosis with a $60 \%$ risk of progression, but also therapeutic exercises $(86.9 \%)$ in cases with a $25 \%$ risk of progression.

Conclusion: There is a growing tendency to consider not only the efficacy, effectiveness and efficiency of treatments, but also their acceptability. This patient-centred aspect is especially more important in areas (like adolescent idiopathic scoliosis) in which there is some evidence on the efficacy of treatments, but not strong and definitive (RCTs). Adolescent idiopathic scoliosis treatments should thus be carefully considered also in the light of their social acceptability.

\section{Background}

Our everyday practice seems to suggest that people prefer, for their children with scoliosis, prevention instead of a "wait and see" approach, even if this prevention of progression implies efforts, expenses, time, and obviously a possible failure. We planned a study to verify this hypothesis.
Children are our future, and therapeutic decisions should reflect this fact: children are not young adults and prevention should be a very important aspect of their care [1].

The long-term natural history of adolescent idiopathic scoliosis (AIS) has recently been described $[2,3]$ : patients with severe curves have a greater incidence of back pain than normal subjects, and reveal minor disabilities, with 
some degree of deformity and cosmetic concerns. There currently exists some evidence, but not strong and definitive (RCTs), demonstrating the efficacy either of conservative or of surgical AIS treatments [4-6]: when compared to a matched normal sample 20 years after treatment, both braced and surgically treated AIS patients had the same function $[7,8]$, quality of life [9], marital status and number of children [10] as the controls, but experienced more back pain $[7,8]$, a progression of pathology $[7,8]$, and limitations of social activities [9] and sexual function [10] (both categories of limitation being more marked in the surgically-treated than in the braced group $[9,10])$. Bracing, whose efficacy has been shown [11-13], causes transient disability and has a psychological impact $[4,8,9,14-16]$; surgery halts progression, but fuses the spine, eliminating its function, and can give rise to complications $[7,9,17]$. There are not conclusive evidences on therapeutic exercises for AIS $[18,11,13,19]$, and school screening has been widely criticized $[15,20]$ even if can be supported $[11,21,22]$.

This lack of strong (RCT's) evidence on natural history and long-term treatment results has prompted a new approach to the making of treatment decisions, with efficacy, effectiveness and efficiency being accompanied by other elements in which patient preferences play a crucial role. It is important both to be aware that treatment decision-making dynamics can alter in the course of the physician-patient relationship, and also to question of the paternalistic model in which the physician plays the dominant role [23]. Several models of physician-patient interaction are discussed in the literature[23] as well as the complexity of patient participation in decision making [24]. As pointed out by Ford et al.[24] "the concept of 'patient choice' originates from the doctrine of informed consent" but efforts are now geared at combining evidence-based medicine (EBM) with patient-centred care to create an evidence-based patient choice (EBPC) approach [25].

Empirical research in this field is mostly devoted to extreme scenarios (in the case of AIS, to decisions regarding surgery [17]) but the problem of eliciting patient preferences is a focus of growing attention. Acceptability can be viewed from a personal perspective, considering the single patient, but also from a wider perspective, i.e., that of the general population (social acceptability). This concept of social acceptability has been applied mainly to the relationship between society and disabled people[26], but it is also applicable to treatment options [25].

The aim of this study was therefore to elicit treatment preferences from the parents of children in the age group at risk of AIS, in order to consider the question of social acceptability: what do families think about the different therapeutic and preventive options for AIS, once they have been made aware of available evidence, advantages and disadvantages of each treatment?

\section{Methods}

We considered children in the age group at risk of AIS, choosing a population of 11-14 year old secondary school pupils. We selected only those not affected by AIS, in order to avoid biased responses (external influences, decisions already reached, etc.) and/or interference with clinical treatments in progress, and administered a questionnaire to their parents. The Study Group (SG) included the 3,162 families of all the children attending a convenience sample of 10 secondary schools in 4 northern Italian regions (Lombardy, Liguria, Veneto and Piedmont).

We chose the instrument of a questionnaire to reach an ample general sample and to avoid as much as possible a direct interference with the population as it could have been happened through educational expert sessions: the questionnaire had to contain all decisional tools. We created a new questionnaire, which included a socio-demographic section and five specific questions (Tables 1 Appendixes 1-2). The decision making tools have been chosen on the basis of current knowledge and consensus in this field $[4-6,13,19,20,27,28]$ so to simulate a situation of EBPC in a real role-playing.

With the aim of validating the questionnaire, we performed both a pre-test survey involving 100 parents (Pretest Group: PG) (Table 2) recruited during a school meeting and a test-retest on 18 subjects in order to evaluate the comprehensibility and repeatability of our questionnaire. At the end of the pre-test survey, we added a single question "What is your opinion on the questionnaire?" that had a four-point ordinal scale answer: "1. easy to understand and answer; 2 . complex to understand and easy to answer; 3. complex to understand and difficult to answer; 4. incomprehensible".

While in the PG the pre-test methodology required a direct interaction with families sample with the only aim of verifying if they understood completely the questionnaire (sometime giving more details and clarifications) and not adding any more information, in the SG the questionnaire was given by the teachers at school together with and headmaster's letter asking children to answer at home with their parents, with restitution the following day (Table 2).

The questionnaires have been collected between March and April 2002. 
Table I: Structure of the questionnaire. AIS: adolescent idiopathic scoliosis. In the rows have been listed: situation (the hypothetical situation in which the responders had to imagine to be before giving their answer), alternatives (hypothetical possibilities in the given situation), decision-making tools (information given to responders to be able to answer), question - which strategy ? (possible choices for the answer).

\begin{tabular}{|c|c|c|c|}
\hline Situation & Alternatives & Decision-making tools & Question Which strategy? \\
\hline $\begin{array}{l}\text { AIS with a } 25 \% \text { risk of progression; } \\
\text { consequence if it progresses: } \\
\text { bracing until growth is complete }\end{array}$ & $\begin{array}{l}\text { - Do nothing, periodic check-ups } \\
\text { Specific physical exercises until } \\
\text { growth is complete, in an attempt } \\
\text { to prevent progression }\end{array}$ & $\begin{array}{l}\text { - scientific evidence (no proof for } \\
\text { or against physical exercises as } \\
\text { means of preventing progression) } \\
\text { - advantages and disadvantages of } \\
\text { each alternative }\end{array}$ & $\begin{array}{l}\text { - Physical exercises until growth is } \\
\text { complete, in an attempt to } \\
\text { prevent/delay bracing } \\
\text { - Periodic check-ups, bracing only } \\
\text { if scoliosis progresses }\end{array}$ \\
\hline $\begin{array}{l}\text { AIS with a } 60 \% \text { risk of progression; } \\
\text { consequence if it progresses: } \\
\text { surgical correction }\end{array}$ & $\begin{array}{l}\text { - Do nothing, periodic check-ups } \\
\text { - Bracing until growth is complete }\end{array}$ & $\begin{array}{l}\text { - scientific evidence (proof of the } \\
\text { efficacy of bracing, but not in all } \\
\text { cases) } \\
\text { - advantages and disadvantages of } \\
\text { each alternative }\end{array}$ & $\begin{array}{l}\text { - Immediate bracing, in order to } \\
\text { avoid surgical correction } \\
\text { - Periodic check-ups, bracing only } \\
\text { if scoliosis progresses } \\
\text { - No bracing at all, periodic check- } \\
\text { ups, surgical correction if scoliosis } \\
\text { progresses }\end{array}$ \\
\hline School screening for AIS & $\begin{array}{l}\text { - not to screen } \\
\text { - to screen }\end{array}$ & $\begin{array}{l}\text { - Scientific evidence (absence of } \\
\text { consensus): pros and cons }\end{array}$ & $\begin{array}{l}\cdot \text { not to screen } \\
\cdot \text { to screen }\end{array}$ \\
\hline
\end{tabular}

\section{Statistical analysis}

Repeatability was assessed with percent agreement, whereas PG and SG data were analysed using percentages (pointwise and 95\% confidence interval estimation). Statistical association has been assessed using $\chi^{2}$ test (level of significance 0.05). Software used: Excel 7.0.

\section{Results}

The questionnaire was considered easy by $8 \%$, complex by $84 \%$, complex and difficult by $8 \%$, and incomprehensible by none of the responders. Test-retest analysis showed agreement ranging from $68.8 \%$ to $88.9 \%$.

The overall SG response rate was 34\% (1,075 responders) and the inter-school response rate ranged from 10 to 67.5\%: an increasing no-response trend (from $1.3 \%$ to $3.4 \%$ ) from the first to the last question was observed. Due to the low response rate obtained, we compared the results of the SG to those of the PG, in which a $100 \%$ response rate had been obtained (Table 2).
The families were found to support the use of screening $(94.8 \%)$ at school. For AIS with a $60 \%$ risk of progression, immediate bracing (76.4\%) was preferred both to observation and bracing in the event of subsequent documented worsening (21\%), and to complete avoidance of bracing with a view to possible future surgery $(2.6 \%)$. In cases presenting a $25 \%$ risk of progression, therapeutic exercises $(86.9 \%)$ were preferred to periodic check-ups, and bracing only if scoliosis progresses (13.1\%) (Table 3 ).

The responses in the SG were not statistically significantly associated with the gender of the responders; neither were they dependent upon the school or the responder's level of education. Opinions on screening were not associated with prior knowledge of AIS or AIS treatments.

\section{Discussion}

People have preventive attitudes: they prefer conservative treatment, but they do not necessarily choose the easiest method or the least aggressive approach. Faced with a

Table 2: Population characteristics and results in the full and pre-test groups: percentages (95\% confidence interval) are reported. AlS: adolescent idiopathic scoliosis.

\begin{tabular}{|c|c|c|c|}
\hline & & Study Sroup (SG) & Pre-test Group (PG) \\
\hline Sample & & 3162 & 100 \\
\hline \multirow[t]{2}{*}{ Gender } & Females & $76.15 \%$ & $83 \%$ \\
\hline & Males & $13.85 \%$ & $17 \%$ \\
\hline \multirow[t]{2}{*}{ Age } & Average & 41.2 & 37.7 \\
\hline & Range & $28-62$ & $29-49$ \\
\hline \multirow[t]{4}{*}{ Education } & primary & $4.37 \%$ & $5 \%$ \\
\hline & secondary & $32.71 \%$ & $28 \%$ \\
\hline & high-school & $51.28 \%$ & $58 \%$ \\
\hline & university & $11.64 \%$ & $9 \%$ \\
\hline
\end{tabular}


Table 3: Results in the full and pre-test groups: percentages ( $95 \%$ confidence interval) are reported. AIS: adolescent idiopathic scoliosis.

\begin{tabular}{|c|c|c|c|}
\hline Question & Answers & Study Sroup (SG) & Pre-test Group (PG) \\
\hline \multirow[t]{2}{*}{ AIS with a $25 \%$ risk of progression } & $\begin{array}{l}\text { Physical exercises until growth is complete in an } \\
\text { attempt avoid/delay bracing }\end{array}$ & $86.90 \%(84.78-88.93)$ & $81 \%(73.31-88.69)$ \\
\hline & Periodic check-ups, bracing only if scoliosis progresses & $13.10 \%(11.07-15.13)$ & $19 \%(11.31-26.69)$ \\
\hline \multirow[t]{3}{*}{ AIS with a $60 \%$ risk of progression } & $\begin{array}{l}\text { Immediate bracing, in an attempt to avoid surgical } \\
\text { correction }\end{array}$ & $76.37 \%(73.17-79.56)$ & $70 \%(67.25-72.75)$ \\
\hline & Periodic check-ups, bracing only if scoliosis progresses & $21.04 \%(17.97-24.10)$ & $28 \%(25.29-30.7 I)$ \\
\hline & $\begin{array}{l}\text { No bracing at all, periodic check-ups, surgical } \\
\text { correction if scoliosis progresses }\end{array}$ & $2.59 \%(1.37-3.82)$ & $2 \%(0.8 I-3.19)$ \\
\hline \multirow[t]{2}{*}{ School screening for AIS } & To screen & $94.8 \%(93.45-96.15)$ & $96 \%(92.16-99.84)$ \\
\hline & Not to screen & $5.2 \%(3.85-6.55)$ & $4 \%(0.16-7.84)$ \\
\hline \multirow[t]{2}{*}{ Relatives - friends with AIS } & Yes & $32.31 \%(29.47-35.15)$ & $36 \%(26.56-45.51)$ \\
\hline & No & $67.69 \%(64.85-70.53)$ & 64\% (54.59-73.4I) \\
\hline \multirow[t]{2}{*}{ Prior knowledge of treatments for AIS } & Yes & $43.55 \%(40.53-46.56)$ & $33 \%(23.78-42.22)$ \\
\hline & No & $56.45 \%(53.44-59.47)$ & $67 \%(57.58-76.22)$ \\
\hline
\end{tabular}

$60 \%$ probability of progression, immediate bracing was preferred to observation and bracing in the event of subsequent documented worsening. Although the lack of scientific evidence for or against physical exercises was stressed [19], as were the costs and psychological burden involved generated by physical exercises, the latter nevertheless emerged as the preferred method of preventing a worsening of AIS in which there is a $25 \%$ risk of progression. Screening was strongly favoured, even after presentation of all the limitations that have prompted many authors to consider it inefficient and, ultimately, of no use [20].

One major problem of the study was the low response rate in the SG. The low response rate was not found to be influenced by the different methods used to motivate and educate responders (headmaster's letter to parents - in the SG
- versus a direct meeting and explanation if needed - in the PG) and is thus probably attributable to the complexity of the questionnaire. The questionnaire was perceived as "complex" by the majority of participants in the PG groups, and questions were changed according to suggestions received to reduce as much as possible this complexity. Anyway, being this study some kind of a "role playing" in which parents had to face an hypothetical situation of pathology of their children that they never thought of before, we both expected, and accepted some degree of complexity due to the need of understanding the situation, the actual literature evidence, as well as "pros and cons" of possible interventions (Table 1). Anyway one of the aim of the study was to be as much neutral as possible, avoiding any interaction between researchers and families (aside from the questionnaire), so to avoid possible influences on the answers, and the methodology was devel-

Table 4: Evolution of indexed literature on idiopathic scoliosis treatment from the period 1970-1974 to the period 1999-2004, based on a Medline search. All the indexed literature is considered, plus the contents of the journal "Spine", whose impact factors is one of the highest in this field.

\begin{tabular}{|c|c|c|c|c|c|c|c|c|}
\hline & \multirow[b]{3}{*}{ First term } & \multirow[b]{3}{*}{ AND } & \multicolumn{6}{|c|}{$\begin{array}{l}\text { Papers published in each period of } \\
\text { five years }\end{array}$} \\
\hline & & & \multicolumn{2}{|c|}{ 1970-74 } & \multicolumn{2}{|c|}{$1980-84$} & \multicolumn{2}{|c|}{ 1999-2003 } \\
\hline & & & $\mathrm{N}^{\circ}$ & $\%$ & $\mathrm{~N}^{\circ}$ & $\%$ & $N^{\circ}$ & $\%$ \\
\hline \multirow[t]{3}{*}{ Medline } & "Idiopathic scoliosis" & & 59 & & 243 & & 495 & \\
\hline & "Idiopathic scoliosis" & surgery & 20 & $33,9 \%$ & 65 & $26,7 \%$ & 268 & $54,1 \%$ \\
\hline & "Idiopathic scoliosis" & $\begin{array}{l}\text { "conservative treatment" OR brace OR braces OR } \\
\text { exercise OR exercises }\end{array}$ & 19 & $32,2 \%$ & 44 & $18,1 \%$ & 94 & $19,0 \%$ \\
\hline \multirow{3}{*}{$\begin{array}{l}\text { Journal "Spine" } \\
\text { (founded in 1978) }\end{array}$} & "Idiopathic scoliosis" & & & & 40 & & 198 & \\
\hline & "Idiopathic scoliosis" & surgery & & & 10 & $25,0 \%$ & 135 & $68,2 \%$ \\
\hline & "Idiopathic scoliosis" & $\begin{array}{l}\text { "conservative treatment" OR brace OR braces OR } \\
\text { exercise OR exercises }\end{array}$ & & & 9 & $22,5 \%$ & 27 & $13,6 \%$ \\
\hline
\end{tabular}


oped accordingly. Being not satisfied with the response rate of less than $40 \%$ in the $\mathrm{SG}$, we introduced a direct comparison with the $\mathrm{PG}$, that hadn't been planned at the start of the study and otherwise we would have avoided. This anyway allowed to verify that the data might, given the similarity of the patterns and sizes of the responses obtained in the two groups, be deemed socially (and clinically, although not statistically) relevant. Moreover, given the similarity of the two group, it could be argued also that the "external interference" applied in this case in the PG group did not have a strong influence on final results.

As stated in the method section, we avoided asking to parents of children already affected by scoliosis to avoid biased responses. The bias that can be introduced in this case is that parents of patients have already formed their ideas, that usually develops from discussions with physicians, radiologists, orthotists, physios, other patients, etc.: moreover, treatments proposed and accepted in this case will for sure drive the thoughts of parents. In this way, this study is some kind of a "role playing" in normal people, asking them to put themselves in the situation as if they had a child with scoliosis: $40 \%$ of a large sample accepted to play this game. Moreover, social acceptability relates to the entire society, and is not what is usually proposed in clinics, i.e. "patient preference"[17]. Another study could (and should) be done in the "biased" sample of scoliosis parents and children to verify their opinions and preferences, but in this case this should be matched and compared with the opinion of the treating team. We have also to point out that presenting the actual evidence, "pros and cons" of treatments to children with scoliosis and their families could represent an external interference with treatment already proposed, possibly being unethical.

Another possible weakness of the study could be not having questioned children directly and alone (they were required to answer together with their parents). We avoided that because of the complexity of the questionnaire, and the fact that usually final decisions on treatment, at the age considered (11-13 years), are reached by parents, eventually together with their children.

The risks of progression considered (25\% and $60 \%$ ) do not match to what have recently been proposed in the International SOSORT Guidelines for scoliosis [29] because this study have been planned and performed much before. At that time we have chosen 25\% risk of progression because it means that you have a low risk, but still some: are people interested in doing some treatment instead of the "wait and see" usual approach even with this so low risk ? Moreover, $60 \%$ risk of progression means that you are at risk, more than $50 \%$, but not in any case very high: do people even in this low-degree risk pre- fer bracing instead of nothing ? These were the answers we were seeking for with this study.

These results, which may seem obvious, are here presented, for the first time, in numerical terms. Acceptability studies generally involve difficult individual decisions, and are conducted in intensive care or surgical settings [17]: this study proposes a new, social approach to the question of acceptability of treatments [30]. Its main limitations are the low response rate in the SG; the "laboratory" setting (questionnaire, normal subjects), the use of proxy responders (parents); the cultural bias, which could be peculiar to northern Italy.

\section{Conclusion}

Even though conservative options for AIS treatment may be more costly, more time-consuming, and generate a greater psychological burden on families and their physicians than more aggressive approaches $[4,6]$, families still appear to have conservative attitudes. These results may have several implications for clinicians, researchers and policy-makers. On the clinical side, when proposing a treatment for AIS, the patient's preferences should carefully be considered, discussing the different therapeutic options [23,24] according to the actual evidence[11]; several decision aids have been developed in literature [31], and one relating to surgery for AIS can be found on the Internet [31]. On the scientific side, the current consensus $[5,6,32]$, and increasing focus of research (Table 4$)$, in favour of aggressive AIS treatments should be carefully reconsidered: our results reveal a gap separating the scientific and everyday worlds. Policy-makers should take into account these results when making decisions about school screening and research funding.

Future research should verify these results in other contexts and with different, possibly less complex instruments.

\section{Authors' contributions}

Both authors contributed to all phases of research

Appendix 1. The original questionnaire used for the study

\section{See Additional file 1}

Appendix 2. English translation of the original questionnaire used for the study. This translation has not been validated in English: it is proposed only to help the readers understand better the methods used. If other researchers would like to use this questionnaire, we strongly suggest to go through a formal trans-cultural validation process.

See Additional file 2 


\section{Additional material}

\section{Additional file 1}

"Appendix 1. The original questionnaire used for the study."

Click here for file

[http://www.biomedcentral.com/content/supplementary/1748-

7161-1-14-S1.doc]

\section{Additional file 2}

"Appendix 2. English translation of the original questionnaire used for the study. This translation has not been validated in English: it is proposed only to help the readers understand better the methods used. If other researchers would like to use this questionnaire, we strongly suggest to go through a formal trans-cultural validation process. "

Click here for file

[http://www.biomedcentral.com/content/supplementary/17487161-1-14-S2.doc]

\section{Acknowledgements}

Caterina Brambilla, PT, for the help in contacting school headmaster's as well as individual teachers, organising questionnaire distribution and collection, and tabulating data.

\section{References}

I. Anynsley-Gent A, Barker M, Burr S, Macfarlane A, Morgan J, Sibert J: Who is speaking for children and adolescents and for their health at the policy level. bmj 2000, 321:229-232.

2. Weinstein SL: Natural history. Spine 1999, 24:2592-2600.

3. Weinstein SL, Dolan LA, Spratt KF, Peterson KK, Spoonamore MJ, Ponseti IV: Health and function of patients with untreated idiopathic scoliosis: a 50-year natural history study. Jama 2003, 289:559-567.

4. Dickson RA: Spinal deformity--adolescent idiopathic scoliosis. Nonoperative treatment. Spine 1999, 24:260I-2606.

5. Sponseller PD: Sizing up scoliosis. Jama 2003, 289:608-609.

6. Bridwell KH: Surgical treatment of idiopathic adolescent scoliosis. Spine 1999, 24:2607-2616.

7. Danielsson $\mathrm{AJ}$, Nachemson $\mathrm{AL}$ : Back pain and function $\mathbf{2 3}$ years after fusion for adolescent idiopathic scoliosis: a case-control study-part II. Spine 2003, 28:E373-83.

8. Danielsson AJ, Nachemson AL: Back pain and function 22 years after brace treatment for adolescent idiopathic scoliosis: a case-control study-part I. Spine 2003, 28:2078-85; discussion 2086.

9. Danielsson AJ, Wiklund I, Pehrsson K, Nachemson AL: Healthrelated quality of life in patients with adolescent idiopathic scoliosis: a matched follow-up at least 20 years after treatment with brace or surgery. Eur Spine J 200I, I 0:278-288.

10. Danielsson AJ, Nachemson AL: Childbearing, curve progression, and sexual function in women 22 years after treatment for adolescent idiopathic scoliosis: a case-control study. Spine 200I, 26: I 449- I 456.

II. Negrini S, Aulisa L, Ferraro C, Fraschini P, Masiero S, Simonazzi P, Tedeschi $C$, Venturin A: Italian guidelines on rehabilitation treatment of adolescents with scoliosis or other spinal deformities. Eura Medicophys 2005, 41:183-201.

12. Nachemson AL, Peterson LE: Effectiveness of treatment with a brace in girls who have adolescent idiopathic scoliosis. A prospective, controlled study based on data from the Brace Study of the Scoliosis Research Society. J Bone Joint Surg Am 1995, 77:815-822.

13. Weiss HR, Negrini S, Hawes MC, Rigo M, Kotwicki T, Grivas TB, Maruyama T, Members of the SOSORT: Physical exercises in the treatment of idiopathic scoliosis at risk of brace treatment SOSORT consensus paper 2005. Scoliosis 2006, I:6 [http:// WWw.isico.it].
14. Climent JM, Sanchez J: Impact of the type of brace on the quality of life of Adolescents with Spine Deformities. Spine 1999, 24:1903-1908.

15. Dickson RA, Weinstein SL: Bracing (and screening)--yes or no? J Bone Joint Surg Br 1999, 81: 193-198.

16. Fallstrom K, Cochran T, Nachemson A: Long-term effects on personality development in patients with adolescent idiopathic scoliosis. Influence of type of treatment. Spine 1986, I I:756-758.

17. Bunch WH, Chapman RG: Patient preferences in surgery for scoliosis. J Bone Joint Surg Am 1985, 67:794-799.

18. Hawes MC: The use of exercises in the treatment of scoliosis: an evidence-based critical review of the literature. Pediatr Rehabil 2003, 6:17|-182.

19. Negrini S, Antonini G, Carabalona R, Minozzi S: Physical exercises as a treatment for adolescent idiopathic scoliosis. A systematic review. Pediatr Rehabil 2003, 6:227-235.

20. Morryssi R: School screening for scoliosis. Spine 1999 , 24:2584-259l.

21. Bunnell WP: Selective screening for scoliosis. Clin Orthop Relat Res 2005:40-45.

22. Winter RB, Lonstein JE: To brace or not to brace: the true value of school screening. Spine 1997, 22: |283-1284.

23. Charles C, Gafni A, Whelan T: Decision-making in the physicianpatient encounter: revisiting the shared treatment decisionmaking model. Soc Sci Med 1999, 49:65I-66I.

24. Gaudagnoli E, Ward P: Patient partecipation in decision-makin. Soc Sci Med 1998, 3:329-339.

25. Ford S, Schofield T, Hope T: What are the ingredients for a successful evidence-based patinet choice consultation?:A qualitative study. Soc Sci Med 2003, 3:589-602.

26. Boumans CE, de Mooij K, Koch PA, van't Hof MA, Zitman FG: Is the social accettabiliy of psichyatric patients decreased by orofacial dyskinesia? Schizophr Bull 1994, 3:339-344.

27. Negrini S, Grivas TB, Kotwicki T, Maruyama T, Rigo M, Weiss HR, the members of the Scientific society On Scoliosis Orthopaedic and Rehabilitation Treatment (SOSORT): Why do we treat adolescent idiopathic scoliosis? What we want to obtain and to avoid for our patients. SOSORT 2005 Consensus paper. Scoliosis 2006, I :4 [http://www.isico.it].

28. Rigo M, Negrini S, Weiss HR, Grivas TB, Maruyama T, Kotwicki T, the members of SOSORT: SOSORT consensus paper on brace action: TLSO biomechanics of correction (investigating the rationale for force vector selection). Scoliosis 2006, I:I I [http:/ /www.isico.it]

29. Weiss HR, Negrini S, Rigo M, Kotwicki T, Hawes MC, Grivas TB, Maruyama T, Landauer F: Indications for conservative management of scoliosis (guidelines). Scoliosis 2006, I:5.

30. Moatti JP, Le Gales C, Seror V, Papiernik E, Henrion R: Social acceptability of HIV screening among pregnant women. AIDS Care 1990, 2:213-222.

31. O'Connor AM, Rostom A, Fiset V, Tetroe J, Entwistle V, LlewellynThomas H, Holmes-Rovner M, Barry M, Jones J: Decision aids for patients facing health treatment or screening decisions: systematic review. Bmj 1999, 3 1 9:731-734.

32. Bradford DS, Tay BK, Hu SS: Adult scoliosis: surgical indications, operative management, complications, and outcomes. Spine 1999, 24:2617-2629.

Publish with BioMed Central and every scientist can read your work free of charge

"BioMed Central will be the most significant development for disseminating the results of biomedical research in our lifetime. "

Sir Paul Nurse, Cancer Research UK

Your research papers will be:

- available free of charge to the entire biomedical community

- peer reviewed and published immediately upon acceptance

- cited in PubMed and archived on PubMed Central

- yours - you keep the copyright

BioMedcentral 